\title{
TEMPERATURE SENSITIVE EFFECTS OF THE NEONICOTINOID CLOTHIANIDIN ON BUMBLEBEE (BOMBUS TERRESTRIS) FORAGING BEHAVIOUR
}

\author{
Pawel J. Kolano', Katrine Borgå2, Anders Nielsen ${ }^{3,1^{*}}$ \\ ${ }^{1}$ Centre for Ecological and Evolutionary Synthesis (CEES), Department of Biosciences, University of Oslo, P.O. Box 1066 \\ Blindern, NO-0316 Oslo, Norway \\ ${ }^{2}$ Section of Aquatic biology and Toxicology, Department of Biosciences, University of Oslo, P.O. Box 1066 Blindern, NO- \\ 0316 Oslo, Norway \\ ${ }^{3}$ Department of Landscape and Biodiversity, Norwegian Institute for Bioeconomy Research (NIBIO), P.O. Box. 115, 1431 \\ Ås
}

Journal of Pollination Ecology, 28(11), 2021, pp 138-152

DOI: $10.26786 / 1920-$

$7603(2021) 633$

Received 20 October 2020, accepted 18 May 2021

*Corresponding author: anders.nielsen@nibio.no

\begin{abstract}
Pollinating insects are an inherent part of most terrestrial ecosystems as they provide a crucial service for most angiosperms, including numerous important crops. A decrease in pollinator populations can therefore have severe consequences for both natural ecosystems and agricultural yields. Pesticide usage has been pointed out as one of the drivers behind pollinator declines. Globally, neonicotinoids are one of the most commonly used insecticides and studies have shown that exposure at sublethal levels can alter foraging behaviour, ultimately negatively affecting survival.

Using a custom-made bumblebee colony monitoring system, we examined how the number and duration of foraging bouts of bumblebees (Bombus terrestris) on an individual level was affected by exposure to low $(6.5 \mu \mathrm{g} / \mathrm{L})$ and high $(10.2 \mu \mathrm{g} / \mathrm{L})$ sublethal concentrations of the neonicotinoid clothianidin via nectar. We also examined possible interaction between clothianidin exposure and abiotic factors (temperature and precipitation), and its impact on foraging bout number and duration.

Exposure to sublethal concentrations of clothianidin increased foraging bout duration in bumblebees. Furthermore, the foraging bout duration decreased with increasing temperature at both exposure concentrations, whereas the unexposed control group was not affected by temperature. Neither number of foraging bouts nor the daily rhythm of foraging bout duration was affected by clothianidin exposure or temperature. The foraging bout duration decreased with increasing precipitation in both exposed and non-exposed groups. However, we did not find any interaction between precipitation and exposure, suggesting that precipitation does not affect toxicity.

Our study shows the importance of semi-natural experiments and accounting for ambient factors when assessing the risk that pesticide exposure may present to pollinators. We conclude that the effect of clothianidin exposure on bumblebee foraging behaviour is temperature sensitive and that local climatic conditions and future climate change scenarios should be considered in risk assessments of clothianidin and other insecticides.
\end{abstract}

Keywords-Foraging bout duration, neonicotinoids, temperature, climate change, individual data

\section{INTRODUCTION}

Bumblebees and other pollinating insects are an inherent part of most terrestrial ecosystems. Currently $46 \%$ of European bumblebee species have declining populations (Nieto et al. 2014). A decrease in insect pollinator populations can have severe consequences for plant communities as $87.5 \%$ of all angiosperms depend on pollination services delivered by pollinators, most of these being insects (Ollerton et al. 2011). It might also negatively affect agricultural production as 
pollinators increase the yields from $35 \%$ of plants used for human consumption (Klein et al. 2007). The main reasons for the declining bumblebee populations include habitat degradation and fragmentation, monocultures, extensive pesticide usage, climate change, diseases and parasites (Potts et al. 2010; Vanbergen \& Initiative 2013; Potts et al. 2016; Sánchez-Bayo \& Wyckhuys 2019). Insecticides used in agriculture to protect crops against parasites and herbivorous insects may negatively affect beneficial, non-target insects, including bees and other pollinators (Kiljanek et al. 2016; Basu \& Chakrabarti 2015; Kumar et al. 2018). Neonicotinoids are a class of neurotoxic insecticides, similar to nicotine in both chemical composition and mode of action. Neonicotinoids interact with Nicotinic Acetylcholine Receptors (nAChRs) (Ihara \& Matsuda 2018), located in the central nervous system of insects, functioning as an antagonist of acetylcholine - a substance that enables the transfer of signals from nervous system to muscles (Brown et al. 2006). The acetylcholine specific enzyme (AChE) is not able to break down neonicotinoids and as such they accumulate in the synaptic cleft and cause continuous generation of muscle stimulating nerve impulses. Low to moderate levels of stimulation can cause convulsions and seizures while high levels result in overstimulation of the nervous system, causing paralysis and death (Nakagawa \& Casida 2001; Brown et al. 2006; Simon-Delso et al. 2015).

The most commonly used neonicotinoids are imidacloprid, thiamethoxam and clothianidin (Goulson 2013). These neonicotinoids can have negative effects on bees, ranging from sublethal to lethal depending on the dose received by the organism (Godfray et al. 2014; Lundin et al. 2015; Tsvetkov et al 2017). Neonicotinoids impair the function of synapses in mushroom bodies in the brain of the insect, leading to reduced learning and memory (Decourtye et al. 2004; Han et al. 2010; Williamson \& Wright 2013; Stanley et al. 2015a; Samuelson et al. 2016), interference with food consumption and foraging (Decourtye et al. 2004; Gill \& Raine 2014; Stanley et al. 2015b; Stanley et al. 2016) and reduced homing ability (Yang et al. 2008; Fischer et al. 2014, Stanley et al. 2016). Further, neonicotinoids can negatively affect the basic motor skills of bees i.e., walking, flying and grooming (Williamson et al 2014); with documented effect such as uncoordinated movements, hyperactivity and convulsions (Blacquière et al. 2012).

Bumblebees are social insects with a complex colony structure and division of labour (Free 1955). An important task for the workers is to provide continuous food supply to ensure proper development of the colony. Foraging involves several complex behaviours including searching for floral resources, flower handling (Stanley et al. 2015b; Stanley \& Raine 2016) and homing ability (Stanley et al. 2016). Any disturbance of these processes might negatively affect bumblebee colony survival and reproduction. Although bumblebees are found in different parts of the world, ranging from hot Mediterranean regions, though wet and humid South America to cold north Scandinavia, they are temperature sensitive (Zamba et al. 2020); Bumblebees cannot take off until their flight muscle temperature is above $30^{\circ} \mathrm{C}$, and the temperature of the thorax during flight must be kept at $30^{\circ} \mathrm{C}$ to $40^{\circ} \mathrm{C}$ (Heinrich 1981; Sanborn 2005). Further, the temperature inside the nest must be maintained at approx. $30^{\circ} \mathrm{C}$ for larvae to develop correctly (Schultze-Motel 1991; Weidenmüller 2004). Recent rapid climate change and increasing temperature is causing overheating problems for bumblebees and is taking a toll on bee populations across the globe (Potts et al. 2010; Kerr et al. 2015; Soroye et al. 2020). In addition, recent studies suggest that the effects of neonicotinoids may also depend on local ambient weather conditions (Boina et al. 2009; Camp \& Buchwalter 2016).

As there is still little knowledge about how interactions between anthropogenic stressors such as neonicotinoids and natural drivers such as ambient temperature affects bumblebees, the aim of this study was to assess how exposure to fieldrealistic sublethal concentrations of the neonicotinoid clothianidin and abiotic factors (temperature and precipitation) affects bumblebee foraging. To address this aim, we developed a monitoring system capable of recording individual bumblebee foraging bouts in natural settings. Once the system was tested and well-functioning, we examined the effects of sublethal clothianidin concentrations on bumblebee (Bombus terrestris) foraging bout duration. We were interested in assessing if foraging bouts were affected by clothianidin, and if this effect was modulated by 
the ambient weather conditions (i.e., temperature and precipitation).

\section{MATERIALS AND METHODS}

\section{DEVELOPMENT OF MONITORING SYSTEM}

To monitor individual bumblebees leaving and entering the colony, we constructed an automated detection system using motion-sensitive cameras. The system consisted of 3 main parts: the colony box, the entrance monitoring box, and a computer with necessary software.

The colony box measured $30 \mathrm{~cm} \times 20 \mathrm{~cm} \times 15$ $\mathrm{cm}$ (length $\mathrm{x}$ width $\mathrm{x}$ height) and was made of untreated pinewood as wood preservatives might repel bumblebees and/or be toxic (Kalnins \& Detroy 1984) (Fig. 1). Based on available bumblebee colony box designs (Sladen 1987; Intenthron 1999), the colony box was divided into 2 chambers; An outer chamber that functioned as an entrance/exit as well as a dedicated place for forage (nectar and pollen) and an inner chamber as the main nesting area. Both chambers were lined with corrugated cardboard to prevent any moisture, waste, and rot from contaminating the floor of the chamber. In addition, the inner chamber was lined with water-repellent cotton wool to provide building materials and insulation for the colony. Ventilation holes were drilled in the sidewalls of the outer chamber and were secured with plastic insect netting to prevent any escape attempts. The lid for the colony box was made from two separate layers - one sheet of transparent
Plexiglas and one sheet of fibreboard. The transparent lid enabled inspection of the colony without opening it, while the fibreboard was used as cover to block sunlight as Bombus terrestris normally nest underground.

The monitoring box housed the camera and the entrance/exit tunnels and measured $16 \mathrm{~cm} \times 10 \mathrm{~cm}$ $x 16 \mathrm{~cm}$ (length $x$ width $x$ height) and was made of untreated pinewood, similar to the colony boxes (Fig. 2). The bottom of the box was divided into 2 tunnels to separate the bumblebees leaving the hive from the ones entering the hive, essentially creating one entrance tunnel and one exit tunnel. A pair of one-way doors was installed in both ends of each tunnel to dictate the movement direction. The doors were made of a thin sheet of transparent plastic mounted on a simple hinge in a 45-degree angle. To avoid blurry and unfocused pictures, the movement speed of the bumblebees had to be reduced. This was achieved by installing a small chokepoint directly beneath the camera. The chokepoints were made of a small plastic cable duct measuring $40 \mathrm{~mm} \times 9 \mathrm{~mm} \times 5 \mathrm{~mm}$ (length $\times$ width $x$ height) attached to the Plexiglass lid. Placed directly above the entrance/exit tunnels was a camera - Logitech HD PRO WEBCAM C920; selected because of its mounting system, with build-in height and tilt adjustments and a tripod mounting bracket, performance (i.e. resolution, frame rate and shutter speed) and low price. To provide constant lighting we mounted a strip of 3 white LEDs (Biltema LED Strips Warm white 3000

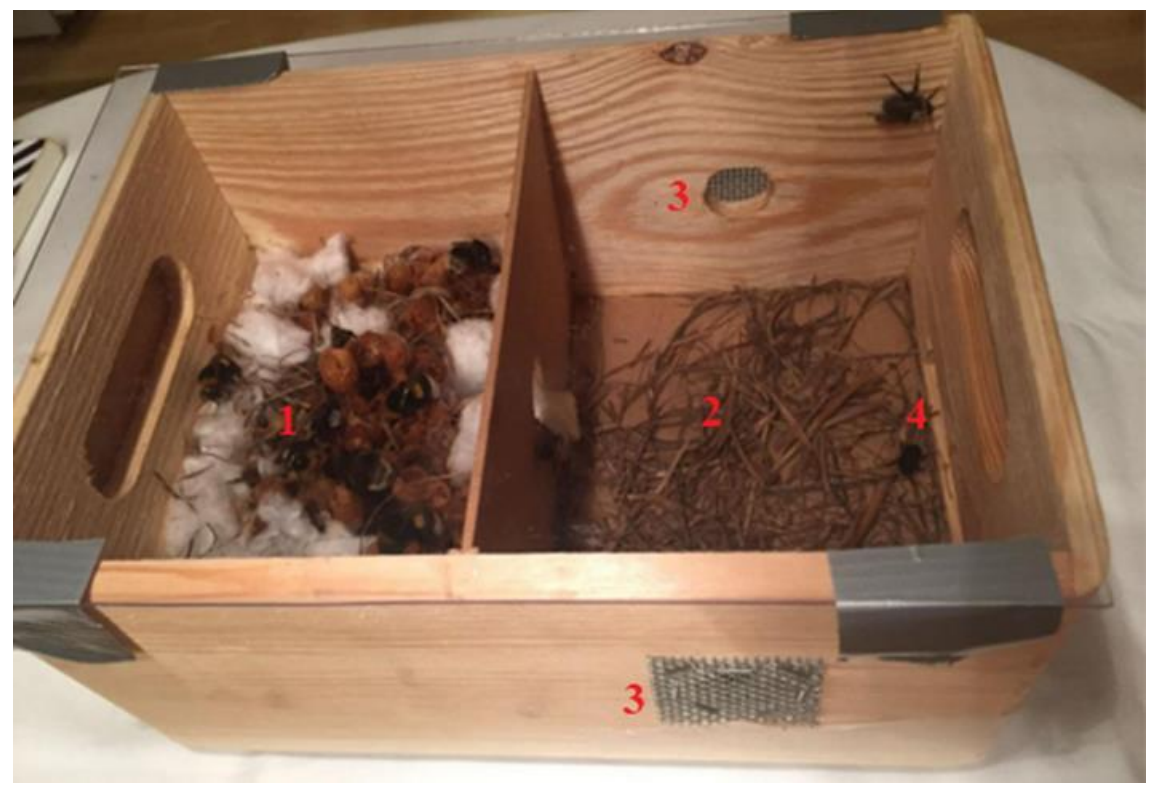

FIGURE 1. Custom made colony box. The box was made of pinewood and measured $30 \mathrm{~cm} \mathrm{x}$ $20 \mathrm{~cm} \times 15 \mathrm{~cm}$. The box was divided into two chambers. The inner chamber (1) was used as the primary nest chamber, while the chamber (2) was used as an entrance (4) and a place for a feeding station. Ventilation holes (3) were drilled into the sides and covered with plastic insect netting. 


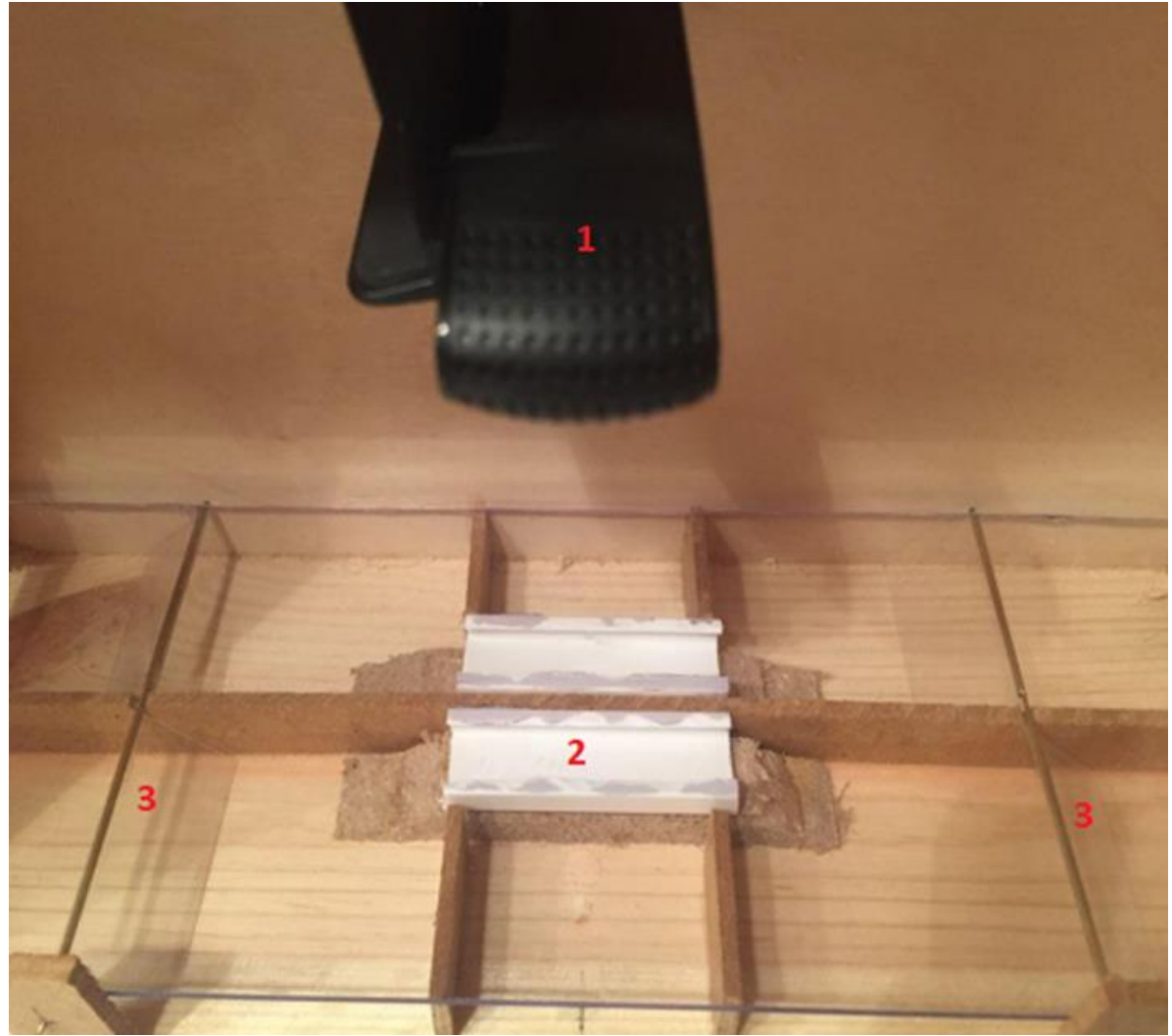

Figure 2. A close-up picture of the inside of the monitoring box, showing the main components. A camera (1) placed directly above a chokepoint (2), which was designed to slow down passing bumblebees. A pair of one-way doors (3) was installed in both tunnels to separate bumblebees entering and leaving the colony.
$\mathrm{K})$ in the top corner of the box. We used LEDs because they do not produce any heat that could affect the bumblebees, they are power efficient, cheap, and easy to mount.

A standard desktop computer (OS: 64-bit Windows 7. Processor: Intel Core i5-2500. Memory: 8GB RAM. Graphics Card: Intel® HD Graphics 2000. Hard Drive: 500 GB) controlled the cameras through the software iSpy 7.2.0.0. We chose this particular software due to it being open source and its numerous functions, enabling the user almost full control of camera parameters. However, any camera surveillance software capable of motion detection should be able to control this system. The cameras were configured to "two-frame motion detection", recording and comparing the current frame with the previous. If the difference between two frames was bigger than a given threshold, the software started taking pictures. The constant lighting inside of the camera box allowed for $98 \%$ sensitivity trigger range i.e., $2 \%$ difference between the frames was enough to trigger the camera.

To identify individual bumblebees, we used a set of software tools called bTools (Gernat et al. 2018) to generate a set of 2048 unique tags called
bCodes. A bCode is a two-dimensional datamatrix and works by the same principle as a $\mathrm{QR}$ code or a barcode (Gernat et al. 2018). Each bCode contains a different value which, when scanned by software provided with bTools, distinguish the codes from one another. This enabled us to register data on activity patterns, i.e. number and duration of foraging bouts, on an individual level. We printed the bCodes on weatherproof paper (Rite in the Rain All-weather Printing Paper) using a standard laser printer at 1200 DPI (dots per inch) print quality, and then cut out using a scalpel. To optimize readability and the process of applying the codes to the bumblebee backs, we used codes of $2.2 \mathrm{~mm} \times 2.2 \mathrm{~mm}$ (length $\times$ width) (Fig. 3). The bCodes were attached to the bumblebee's thorax between the wings (Fig. 3), using a small drop of Loctite Super Glue.

\section{EXPERIMENTAL SETUP}

To measure the effects of clothianidin on foraging behaviour of individual bumblebees, we designed a semi-natural experiment involving 36 Bombus terrestris colonies. The colonies were purchased from the company Bombus Natur AS, Bryne, South-Western Norway. The colonies were divided into 6 replicates. Each replicate contained 


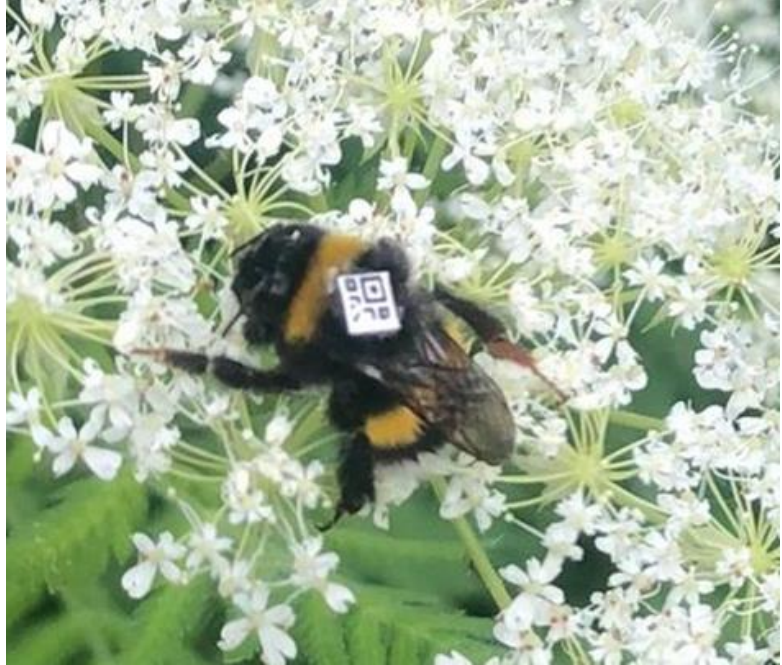

Figure 3. Bumblebee worker marked with bCode foraging on Anthriscus sylvestris flowers in Urtehagen at University of Oslo (approx. 50 metres from the monitoring stations and colony boxes). Note that the bCode recognition software was able to correctly recognize and identify the tag. Photo: Malin R. Aarønes. Date 29 May 2019

6 colonies of which 2 acted as control $(0 \mu \mathrm{g} / \mathrm{L}), 2$ received low concentration $(6.5 \mu \mathrm{g} / \mathrm{L})$ and 2 received the high concentration $(10.2 \mu \mathrm{g} / \mathrm{L})$ of clothianidin. The selected concentrations were within field-realistic concentrations, based on quantified residuals of clothianidin in leaves, nectar and pollen (Xu et al. 2015; Mogren et al.2016; Botías et al. 2016).

The concentrations of $6.5 \mu \mathrm{g} / \mathrm{L}$ and $10.2 \mu \mathrm{g} / \mathrm{L}$ clothianidin were made using a simple dilution method. The accuracy of the dilution method was confirmed by High-performance liquid chromatography-mass spectrometry (HPLC-MS) (Aarønes 2019). The dilution steps were designed in such a way that the volume of the solution (15 $\mathrm{ml}$ ) added to the nectar tank in the last step of dilution was the same for all treatment levels. Concentrations were assigned to the colonies randomly by a third party, not related to the project, allowing the experiment to be double blinded from the start of the exposure period. The experiment was unblinded at the data-analysis step.

Each replicate followed the exact same procedure from the start to the end of the experiment, starting with the exposure period (9 days), followed by 1 day of marking and the release and observation period of 7 days. Bumblebees were exposed ad libitum through artificial nectar for 9 days in a climate-controlled room at $18^{\circ} \mathrm{C}$. For the first 4 days of the exposure period, we used the original plastic containers in which the colonies were delivered in. On the $5^{\text {th }}$ day of the exposure, the colonies (all individuals and the nest structure) were transferred from the original plastic containers to custom-made colony boxes. For the rest of the exposure period, the colonies were left undisturbed to acclimatize to the new boxes. During the whole exposure period, the colonies were fed pollen substitute (Bifor Kvikkpoll) in form of a patty, containing soy flour, brewer's yeast, grape and fruit sugar, cane sugar, minerals, vitamins, and water. Pollen is the main source for proteins and lipids (Vaudo et al. 2016) and is necessary for the development of the colony. Bombus Natur provided pollen for the duration of the transit and the first 4 days of the experiment and another $15 \mathrm{~g}$ of pollen was provided when the colonies were transferred to the custom-made boxes.

At the end of the $9^{\text {th }}$ day of exposure, the nectar feeder was removed and 30 individuals from each hive were marked. After marking the individuals, fresh pollen patty was provided $(6 \mathrm{~g})$, and colonies left inside for an additional 24 hours to calm down and repair any damages done to the nest under the marking process. After the cooldown period, colonies were connected to the monitoring stations placed outside the Animal Facility (IBV-ANIMAL) at University of Oslo for 7 days, and bumblebees were allowed to forage freely. All 5 replicates were run in quick succession, with 1 day pause between replicates.

The temperature and precipitation were measured by Norwegian Meteorological Institute (MET Norway), located approximately 530 metres from the study site, and downloaded from https://seklima.met.no/. The ambient temperature was measured in ${ }^{\circ} \mathrm{C}$, at hourly intervals. We used approx function provided with the base R 4.0.5 for Windows to interpolate the hourly temperature data into minutes. The temperature was assigned to foraging bouts based on the time when the bumblebee first left the colony (start of the foraging bout). Precipitation was measured as daily average in millimetres $(\mathrm{mm})$, which corresponds to litres per square metre $\left(1 / \mathrm{m}^{2}\right)$. 


\section{DATA TREATMENT}

We conducted the foraging behaviour observation on queenright colonies only, i.e., colonies with a single queen. Bumblebees are social insects with a social order based on dominance. Having multiple queens or no queen might promote aggressiveness between workers and unwanted behaviour changes which could influence the results of this study (Free 1955; Sibbald \& Plowright 2013). To reduce the variation in colony condition, we excluded all colonies without ( 5 colonies) or with multiple queens (2 colonies), colonies with fewer than 30 workers (2 colonies) and colonies with more than 200 workers ( 2 colonies) from the experiment at the end of the exposure period. The foraging behaviour observation was conducted on 25 colonies - control group (not exposed - 9 colonies), low concentration group $(6.5 \mu \mathrm{g} / \mathrm{L}-9$ colonies $)$ and high concentration group (10.2 $\mu \mathrm{g} / \mathrm{L}-7$ colonies).

To account for the inability of the system to differentiate between real foraging bouts and training bouts, we excluded bumblebees that have taken less than 3 foraging bouts, and only included foraging bout no. 3 and later (the first 2 bouts were defined as training flights and were not included in the analyses). We also excluded foraging bouts shorter than 5 minutes as they were most likely not real foraging bouts.

To determine if the test groups were statistically different from each other, a One-Way
ANOVA test was used together with a Tukey HSD Post-Hoc test in IBM SPSS Statistics for Windows, Version 27. We used a generalized linear mixed model (GLMM) approach to describe the changes to foraging bout duration in response to exposure and several environmental variables (Tab. I). For model selection, we made a list of models with all possible permutations of variables and interactions between the variables. To account for the variation between the replicates, colonies, and individual bumblebees, all models were run with the same nested random factor defined as $(11+$ Replicate/Hive/Bee). The GLMM with the lowest AIC score (51323.65) was chosen as the best and included an interaction between the exposure and interpolated temperature, time of day, mean daily precipitation, and number days into the release period. The next-best model had a $\triangle$ AIC of 17.56 compared with the best model suggesting the best model to be substantially better.

\section{RESULTS}

\section{DETECTION SYSTEM AND NUMBER OF FORAGING BOUTS}

During the experiment, the 6 monitoring stations worked continuously for 35 days (5 replicates $x 7$ days per replicate). In total 5,613,031 pictures were taken. The size of a single picture averaged on $65.5 \mathrm{~kb}$ (after automatic resolution adjustment and file compression) and all pictures together occupied $368 \mathrm{~GB}$ of hard drive space.

Table I.Overview of the explanatory variables used in the GLMM explaining the changes to foraging bout duration.

\begin{tabular}{|c|c|c|}
\hline Explanatory variable & & Definition \\
\hline Treatment & & $\begin{array}{l}\text { Categorical variable with } 3 \text { different levels of clothianidin exposure: Control } \\
(0 \mu \mathrm{g} / \mathrm{L}) \text {, Low }(6.5 \mu \mathrm{g} / \mathrm{L}) \text { and High }(10.2 \mu \mathrm{g} / \mathrm{L})\end{array}$ \\
\hline Interp_Temperature & & $\begin{array}{l}\text { Continuous variable of the temperature measured at Norwegian } \\
\text { Meteorological Institute (MET), } 530 \text { metres from the study site measured } \\
\text { every hour and interpolated into temperature every minute. Measured in }{ }^{\circ} \mathrm{C} \text {. }\end{array}$ \\
\hline \multirow[t]{2}{*}{ Time_of_Day } & $\sin 1+\cos 1$ & $\begin{array}{l}\text { Cyclic time of day variable, } \sin 1+\cos 1 \text { used as time-of-day covariate. Based on } \\
\text { a formula } \sin \left(2^{*} \mathrm{pi}^{*} \text { Minutes after midnight }\right) \text { and } \cos \left(2^{*} \mathrm{pi}^{*} \text { Minutes after }\right. \\
\text { midnight }) \text {. }\end{array}$ \\
\hline & $\sin 2+\cos 2$ & $\begin{array}{l}\sin 2+\cos 2 \text { is higher order of the time-of-day variable. Based on a formula } \\
\sin \left(2 * 2^{*} \mathrm{pi}^{*} \text { Minutes after midnight }\right) \text { and } \cos \left(2 * 2^{*} \mathrm{pi}^{*} \text { Minutes after midnight }\right) .\end{array}$ \\
\hline DailyPrecipitation & & $\begin{array}{l}\text { Continuous variable of the mean daily precipitation measured at Norwegian } \\
\text { Meteorological Institute (MET), } 530 \text { metres from the study site. Measured in } \\
\text { millimetres. }\end{array}$ \\
\hline DatelD & & $\begin{array}{l}\text { Continuous variable with the number of days into release period ranging } \\
\text { from } 1 \text { to } 7,1 \text { being the first day and } 7 \text { being the last day of observations. }\end{array}$ \\
\hline (1 |Replicate/HivelD/BeeID) & & $\begin{array}{l}\text { Nested random variable. Used to describe variance between replicates } \\
\text { (categorical variable Replicate), hives (categorical variable HivelD) and } \\
\text { individual workers within the hives (categorical variable BeeID) }\end{array}$ \\
\hline
\end{tabular}


Table II. Overview of the One-way ANOVA analysis for differences in foraging bout duration between test groups.

\begin{tabular}{llllll}
\hline & Sum of Squares & df & Mean Square & F & Sig. \\
\hline Between Groups & 217295.619 & 2 & 108647.809 & 5.346 & .005 \\
Within Groups & 82819174.828 & 4075 & 20323.724 & & \\
Total & 83036470.447 & 4077 & & & \\
\hline
\end{tabular}

Table III. Descriptive statistics for the One-way ANOVA analysis for differences in foraging bout duration between test groups.

\begin{tabular}{lllllllll}
\hline & & & & \multicolumn{5}{c}{$95 \%$ Confidence Interval for Mean } \\
& $\mathrm{N}$ & Mean & $\begin{array}{l}\text { Std. } \\
\text { Deviation }\end{array}$ & Std. Error & Lower Bound & $\begin{array}{l}\text { Upper } \\
\text { Bound }\end{array}$ & Minimum & Maximum \\
\hline Control & 1461 & 59.64 & 99.907 & 2.614 & 54.51 & 64.77 & 6 & 1293 \\
High & 1351 & 96.29 & 171.682 & 4.671 & 67.12 & 85.45 & 6 & 1395 \\
Low & 1266 & 92.75 & 149.982 & 4.215 & 64.48 & 81.02 & 6 & 1293 \\
Total & 4078 & 69.23 & 142.713 & 2.235 & 64.84 & 73.61 & 6 & 1395 \\
\hline
\end{tabular}

Table IV. Post hoc analysis of the One-Way ANOVA analysis, showing the siginificant differences between different treatment groups.

\begin{tabular}{|c|c|c|c|c|c|c|}
\hline \multicolumn{7}{|l|}{ Tukey HSD } \\
\hline \multirow[t]{2}{*}{ (I) Exposure } & \multirow[t]{2}{*}{ (J) Exposure } & \multirow{2}{*}{$\begin{array}{l}\text { Mean } \\
\text { Difference (I-J) }\end{array}$} & \multirow[t]{2}{*}{ Std. Error } & \multirow[t]{2}{*}{ Sig. } & \multicolumn{2}{|c|}{ 95\% Confidence Interval } \\
\hline & & & & & Lower Bound & Upper Bound \\
\hline \multirow[t]{2}{*}{ Control } & High & $-36.645^{*}$ & $5 \cdot 381$ & .006 & -29.26 & -4.03 \\
\hline & Low & $-33.110 *$ & 5.474 & .044 & -25.94 & -.28 \\
\hline \multirow[t]{2}{*}{ High } & Control & $36.645^{*}$ & $5 \cdot 381$ & .006 & 4.03 & 29.26 \\
\hline & Low & 3.535 & 5.576 & .801 & -9.54 & 16.61 \\
\hline \multirow[t]{2}{*}{ Low } & Control & $33.110^{*}$ & 5.474 & .044 & .28 & 25.94 \\
\hline & High & -3.535 & 5.576 & .801 & -16.61 & $9 \cdot 54$ \\
\hline
\end{tabular}

The average detection rate (defined as number of successful detections divided by the total number of detections (also including those where the identity of the bCode could not be defined) was $86.4 \%$. The detection rates varied between the monitoring stations, with the highest detection rate at $89.3 \%$ (Station 4 ) and the lowest at $79.1 \%$ (Station $1)$.

During the release and observation, the system registered 4078 unique foraging bouts - control group $(N=1461$ (162 per hive)), low concentration group $(N=1266(140$ per hive $))$ and high concentration group $(N=1351$ (193 per hive)).

\section{FORAGING BOUT DURATION}

There was a statistically significant difference in foraging bout duration between the groups [ANOVA; $F_{2,4075}=5.35, P=0.005$ ] (Tab. II). Bumblebees exposed to low concentration of clothianidin (Tukey HSD; $M=72.75, S D=149.71$ ) made significantly longer foraging bouts compared to the non-exposed bumblebees (Tukey HSD; $M=59.24, S D=99.91)(P=0.044)$. Similarly, bumblebees exposed to high concentration of clothianidin (Tukey HSD; $M=76.29, S D=171.68$ ) also made significantly longer foraging bout compared to the non-exposed bumblebees $(P=$ 
0.006) (Tab. III). However, the foraging bout duration did not differ between the exposure concentrations (Tukey HSD; $P=0.801$; Tab. IV).

Ambient temperature by itself did not have a significant effect on foraging bout duration for either group of exposed bumblebees (GLMM; $P=$ $0.786, C I[-1.99,2.63])$. However, there was a significant interaction between the temperature and the level of exposure to clothianidin. Both low $(6.5 \mu \mathrm{g} / \mathrm{L})$ and high exposure $(10.2 \mu \mathrm{g} / \mathrm{L})$ groups were significantly different from the control group in their relationship between temperature and foraging bout duration. On average, an increase of ambient temperature by $1^{\circ} \mathrm{C}$ resulted in a decrease of foraging bout duration by 1.91 minutes for the low exposure group (GLMM; $P=0.049, C I[-5.10$, 1.29]) and a decrease of foraging bout duration by 3.02 minutes for the high exposure group (GLMM; $P=0.032, C I[-6.40,-0.27])$ when compared to the control group (Fig. 4). Low and high groups did not significantly differ from each other. The foraging bout duration of the bumblebees exposed to clothianidin was longer than the foraging bout duration of the non-exposed control group throughout the whole temperature range (Fig. 4). The foraging bout duration for the control group was rather stable; 106 minutes at $10^{\circ} \mathrm{C}$ with a slight increase to 112 minutes at $28^{\circ} \mathrm{C}$. The effects of clothianidin exposure were more apparent at low temperatures; at $10^{\circ} \mathrm{C}$ the bout duration for the low exposure group was 150 minutes and 173 minutes for the high exposure group (Fig. 4). The foraging bout duration for the exposed bumblebees decreased with increasing ambient temperature, resulting in foraging bout duration of 124 minutes for the low exposure group and 127 minutes for the high exposure group at $28^{\circ} \mathrm{C}$ (Fig. 4).

An increase in mean daily precipitation decreased foraging bout duration - on average, a 1 $\mathrm{mm}$ increase in daily precipitation, decreased foraging bout duration by 0.96 minutes (GLMM; $P$ $=0.005, C I[-1.64,-0.28])$. There was no significant difference in the decrease of foraging bout duration between the exposure groups, nor were there any significant interactions between the daily precipitation and other factors.

The time of day had a significant effect on the duration of the foraging bouts of the bumblebees (Tab. V). Most of the foraging bouts occurred between 07:00 and 23:00 $(N=4046)$, with very few bouts during the night $(23: 00-07: 00)(N=32)$ (Fig. $5)$. The highest activity window for all groups was between 18:00 and 19:00 (Fig. 5). The foraging bout duration did vary significantly throughout the day. The shortest bouts were taken between 01:00 and 04:00 and the longest between 09:00 and 18:00 (Fig. 6). There was no difference in the distribution of the foraging bouts during the day between the test groups. The exposure to clothianidin did not affect the daily rhythm of foraging bout duration and no significant interaction between the time of day and other factors was found.

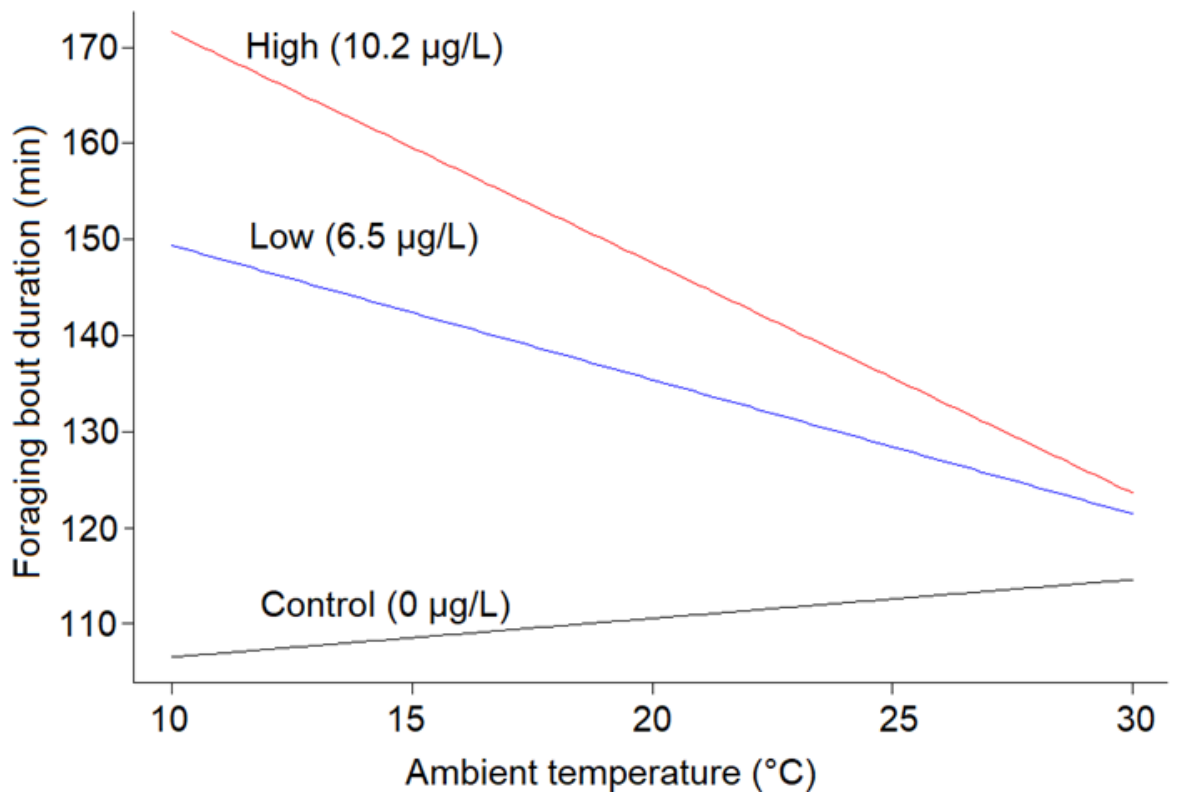

FIGURE 4. Temperature dependency for the different treatment levels (black control (not exposed), blue low exposure $(6.5 \mu \mathrm{g} / \mathrm{L})$, red high exposure $(10.2 \mu \mathrm{g} / \mathrm{L}))$ based on the GLMM estimates, given that all other fixed effects are kept on their average values. Y-axis represents the foraging bout duration in minutes, and $\mathrm{x}$-axis the ambient temperature in Celsius. 
Table V. Generalized linear mixed-effects model (GLMM) for the effects of clothianidin exposure and abiotic factors on foraging bout duration in bumblebees with replicate, colony and individual bees as random variable.

Imer(formula = TimeOUT factor(Exposure) $*$ interp_temperature $+\sin 1+\cos 1+\sin 2+\cos 2+$ DailyPrecipitation + DatelD + (1|Replicate/HiveID/BeeID)

\begin{tabular}{|c|c|c|c|c|c|c|}
\hline \multicolumn{2}{|l|}{ Fixed effects: } & Estimate $[95 \% \mathrm{Cl}]$ & SE & df & t-value & $\mathrm{p}$-value \\
\hline \multicolumn{2}{|l|}{ (Intercept) } & $139.58[42.89,236.27]$ & 49.33 & 6 & 2.83 & 0.029 \\
\hline \multicolumn{2}{|c|}{ Treatment High } & $64.51[35.56,152.46]$ & 29.57 & 1316 & 3.19 & 0.001 \\
\hline \multicolumn{2}{|c|}{ Treatment Low } & $50.33[0.26,120.41]$ & 30.65 & 1640 & 2.24 & 0.049 \\
\hline \multicolumn{2}{|c|}{ Interp_Temperature } & $0.32[-1.99,2.63]$ & 1.18 & 4039 & 0.19 & 0.786 \\
\hline \multirow[t]{4}{*}{ Time_of_day } & $\sin 1$ & $25.50[7.92,43.10]$ & 8.98 & 3905 & 2.80 & 0.005 \\
\hline & $\cos 2$ & $35.50[23.69,47.32]$ & 6.02 & 3860 & 5.90 & $<.001$ \\
\hline & $\sin 2$ & $15.50[5.27,25.72]$ & 5.22 & 3838 & 2.97 & 0.003 \\
\hline & $\cos 2$ & $2.79[-5.91,11.50]$ & 4.43 & 3858 & 2.63 & 0.009 \\
\hline \multicolumn{2}{|c|}{ DailyPrecipitation } & $-0.96[-1.64,-0.28]$ & 0.35 & 3940 & -2.78 & 0.005 \\
\hline \multicolumn{2}{|l|}{ DatelD } & $-0.73[-3.47,2.00]$ & 1.40 & 4033 & -0.52 & 0.601 \\
\hline \multicolumn{2}{|c|}{$\begin{array}{l}\text { Interaction Treatment high: } \\
\text { Interp_Temperature }\end{array}$} & $-3.02[-6.40,-0.27]$ & 1.56 & 3989 & -2.14 & 0.032 \\
\hline \multicolumn{2}{|c|}{$\begin{array}{l}\text { Interaction Treatment Low: } \\
\text { Interp_Temperature }\end{array}$} & $-1.91[-5.10,1.29]$ & 1.63 & 4049 & -1.97 & 0.049 \\
\hline
\end{tabular}

\section{Discussion}

\section{THE MONITORING SYSTEM}

Most of the monitoring systems are based on RFID technology (Radio Frequency Identification), but there are also optical based systems, for example a system called BEEtag (Crall et al. 2015). Our system was developed to enable collection of data on foraging bout durations from individual bumblebees from multiple colonies at the same time at an affordable price.

Our monitoring system has some advantages over the existing monitoring solutions, with cost being the primary advantage. The most expensive part were the cameras (purchased for $~ € 70$ each in 2019). Computers used to control the cameras were old computers from 2013, rescued from the recycle bin. In comparison, the camera used in BEEtag system was an entry level Nikon DSLR camera, then available for $\sim 500$ USD (Crall et al. 2015). The bCodes used in our study, were printed on waterproof paper at $€ 0.26$ per 768 bCodes. The initial cost of building our system (estimated at around $€ 80$ per colony), together with low cost of marking per individual, allows for collection of foraging bout data from large colonies at an extremely low cost compared to other monitoring systems.

Another advantage of our system is the efficient storage of data. During the course of the experiment, more than 5 million pictures were taken, occupying 368 GB of hard drive space. This amount of data can be easily stored on an external hard drive or a Secure Digital (SD) card, greatly simplifying the process of transferring the data between computers. The software used to control the cameras, also enables direct cloud storage of pictures as well as remote access to both cloud storage and camera control (an internet connection is required for this function).

Compared to other solutions, our system is capable of monitoring 3 colonies per 1 computer at the same time. However, this number was limited by the hardware of old computers. Theoretical number of active cameras at the same time with resolution of $960 \times 720$ pixels at 30 frames by second, using modern computers would be $9-12$ cameras per 1 computer.

One main drawbacks of our system are the bCodes themselves. Small printing errors or visual 


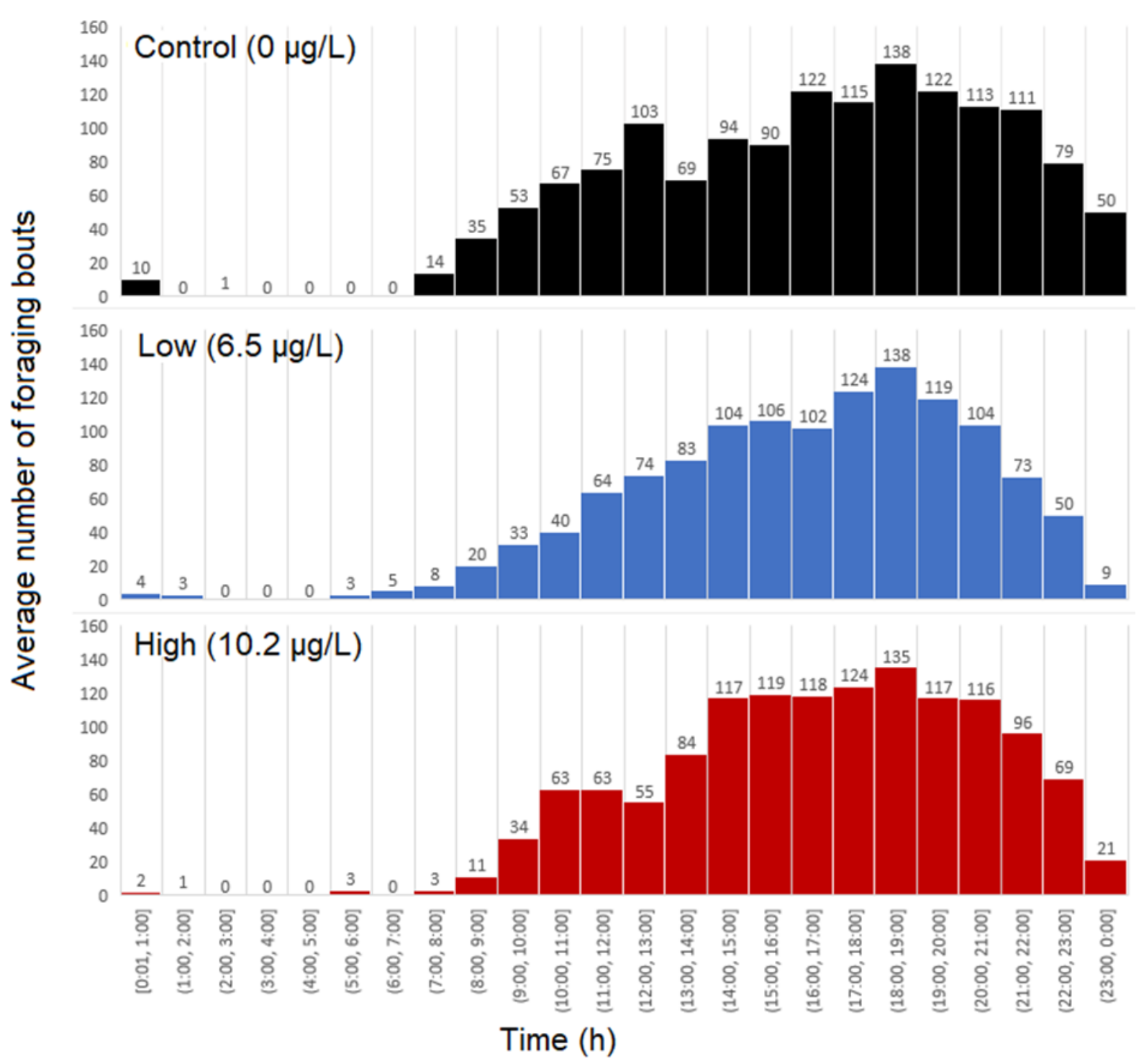

Figure 5. Histogram of the average number of foraging bouts per hour for the different test groups (black - control (not exposed), blue - low exposure $(6.5 \mu \mathrm{g} / \mathrm{L})$, red - high exposure $(10.2 \mu \mathrm{g} / \mathrm{L}))$. There was no significant difference between the test groups. Main activity window for the bumblebees in this study was between 07:00 and 23:00, with little to no activity during the night (00:00 to 07:00).

contamination of the tag is a huge challenge in every optical based system. However, bCodes are quite small $(2 \mathrm{~mm} \times 2 \mathrm{~mm})$ and fairly complex, meaning even a small obstruction/imperfection can result in a non-recognizable tag. Still, our system achieved an average detection rate of $86.4 \%$; i.e., $13.6 \%$ foraging bout were not recorded, with visual obstruction accounting for most of the failed detections. Contrarily, BEEtag system uses tags that are far less complicated and thus, more resistant to visual impairment, with and overall correct identification rate of $99.97 \%$ (Crall et al. 2015). BEEtag system also offers enhanced functionality, like for example spatial position tracking of individual bumblebees inside the nest area, user-friendly interface, and video file processing abilities (Crall et al. 2015). Our method of using low-cost cameras and motion detection can be easily combined with BEEtag tags for additional functionality and better user interface in future studies.

Another drawback of our system was the inability to measure pollen and nectar loads brough back from the foraging trips. A load cell or a precision scale incorporated into the system, would add the ability to combine the foraging bout duration data with the pollen/nectar loads, giving us the insight on how pesticides affect foraging efficiency. Other improvements could include 3D 


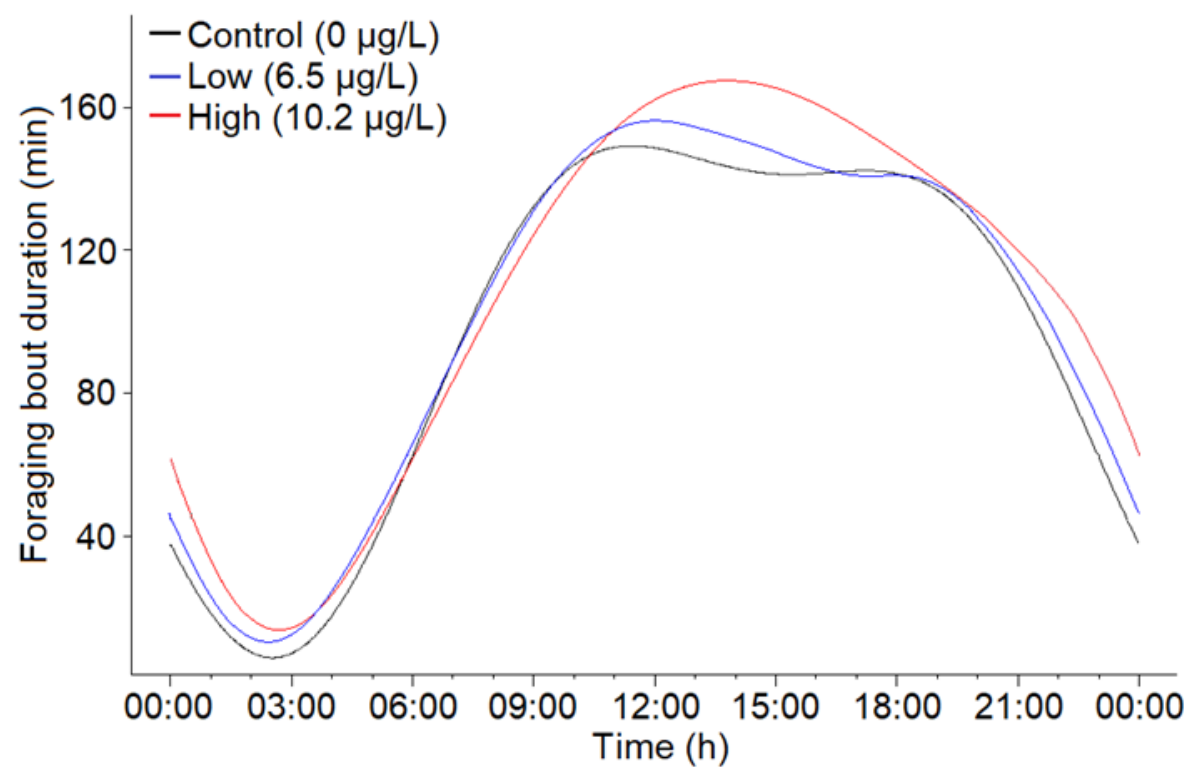

FIGURE 6. Variation in foraging bout duration during the day for the different treatment levels (black - control (not exposed), blue - low exposure $(6.5 \mu \mathrm{g} / \mathrm{L})$, red - high exposure $(10.2 \mu \mathrm{g} / \mathrm{L}))$ The variation in foraging bout duration during the day is based on the Time of Day variable $\left(\sin \left(2 * 2 * \mathrm{pi}^{*}\right.\right.$ Minutes after midnight $)+\cos \left(2 * 2 * \mathrm{pi}^{*}\right.$ Minutes after midnight ) and the GLMM estimates. Y-axis represents the foraging bout duration in minutes, and $x$-axis the time of day in hours (24-hour clock).

printing of the camera-boxes, which would hugely speed up the manufacturing process, while also allowing for higher precision and more intricate designs of both nesting- and camera boxes. Our system can be adapted to utilize a single-board computer, like Raspberry Pi, instead of a camera and a separate computer. This would make this system fieldable, without compromising its performance.

\section{FORAGING BOUT DURATION}

In this study the forging bout duration was significantly affected by the exposure to clothianidin. Both low and high exposure groups made foraging bouts that were significantly longer than the foraging bouts of the control group. That said, the low and high control groups were not significantly different from each other, which means that $6.5 \mu \mathrm{g} / \mathrm{L}$ concentration and $10.2 \mu \mathrm{g} / \mathrm{L}$ concentration have similar effects on bumblebees. Studies with similar experimental setup have shown results alike ours (e.g., Gill et al. 2012; Gill \& Raine 2014; Feltham et al. 2014; Stanley et al. 2015a; Stanley et al. 2016; Samuelson et al. 2016). Decrease in foraging effectiveness has been attributed to several different mechanisms, ranging from learning and memory impairment (Stanley et al. 2015a; Samuelson et al. 2016), chronic behaviour impairment (Gill \& Raine 2014) and reduction in flower handling efficiency (Phelps et al. 2020). However, as we did only measure the foraging bout duration, we are unable to determine the exact cause for the extended foraging bouts. Nonetheless, we did find a connection between abiotic factors and the exposure to clothianidin which could help in understanding the changes in foraging bout duration.

Ambient temperature by itself did not have a significant effect on the foraging bout duration. The ambient temperature during the release and observation period was between $9.5-28^{\circ} \mathrm{C}$, which is within the optimal temperature range for the bumblebees (Oyen \& Dillon 2018). However, there was a significant interaction between the temperature and the level of exposure to clothianidin. Bumblebees cannot take off until the temperature of their flight muscles is above $30^{\circ} \mathrm{C}$ and thoracic temperature during flight must be maintained between $30^{\circ} \mathrm{C}$ and $40^{\circ} \mathrm{C}$ (Sanborn 2005). Neonicotinoids have been shown to alter the non-flight thermoregulation and metabolism in both honeybees (Tosi et al. 2016) and bumblebees (Potts et al. 2018). An exposure to $5 \mathrm{ppb}$ resulted in a thoracic temperature drop by $1.5-2^{\circ} \mathrm{C}$, which equated to $15-20 \%$ decrease in metabolic rate in $B$. terrestris (Potts et al. 2018). Such reduction in metabolic rate can have detrimental effects on flight performance at lower temperatures. An increase in ambient temperature would counteract the reduced thermogenesis and metabolism, aiding bumblebees in achieving the required thoracic temperature. Bumblebees have previously been shown to express biphasic responses to neonicotinoid exposure, in which a low dose exposure stimulated warming rates but inhibited 
them at higher exposure (Potts et al. 2018). The counteractive effect of ambient temperature on the neonicotinoid-induced reduction in thoracic temperature, as well as a possible hormetic response could explain why the foraging bout duration of the exposed bumblebees in our study decreased to approach the control, with increasing temperature. However, it is worth noting that we did not manipulate the ambient temperature in any way. This means that we cannot conclude any causal connection between temperature and foraging behaviour.

Although bumblebees are quite robust and able to withstand rain and wind to some degree (Lundberg 1980; Lawson \& Rands 2019), the foraging bout duration decreased with increasing precipitation. Flying in the rain requires more energy and decreased visibility might disrupt or weaken sensory signals. This can increase the possibility of a bumblebee forager using more resources than it is able to gather (Lawson \& Rands 2019). Precipitation might also affect the availability of food sources as many flowers close their coronas during rain to protect pollen and nectar from being diluted and/or removed by rain droplets (Bynum \& Smith 2001; Lawson \& Rands 2019). Thus, wet conditions might discourage foragers from continuing the foraging bout and prompt them to return to the colony. There was no interaction between precipitation and clothianidin exposure, thus the effect of precipitation on clothianidin toxicity was the same at both exposure level.We found no interaction between exposure level and diurnal rhythm suggesting that clothianidin exposure does not affect this behaviour within the exposure range. Bumblebees have a diurnal rhythm, which mean that they are most active during the daylight. Tasman et al. (2020) showed that exposure to imidacloprid at a concentration of $10 \mu \mathrm{g} / \mathrm{L}$ can affect the circadian rhythm in bumblebees, increasing night-time activity and decreasing daytime activity. Tackenberg et al. (2020) have found similar results for honeybees. However, in our study there was little to no activity during the night hours. Most of the foraging activity began from 07:00, steadily increasing though the day. However, there was no significant difference between the exposed groups and the control; all followed the same diurnal rhythm. The extent of the active period can be explained by the lighting condition in Norway at the time of the experiment; the sunset was between 23:00 to 00:00 and the sunrise around 04:00, resulting in close to 19-20 hours of daylight.

\section{CONCLUSION}

Our cost effecting test system worked very well to obtain individual bumble bee observations on the behaviour regarding foraging bouts. The exposure to sublethal concentrations of clothianidin extended the foraging bout duration, with longest extension at low temperature and decreasing difference (hence longer duration) to control with increasing temperature. Although we have not monitored the behavioural change during the foraging bouts and therefore cannot identify the exact mechanism for the observed changes in foraging bout duration, we have shown that the effects of clothianidin exposure are context dependent. We conclude that the effect of clothianidin exposure on bumblebee foraging behaviour is temperature sensitive and that local climatic conditions and future climate change scenarios might alter the effects of clothianidin. We therefore suggest that local climate conditions should be considered in risk assessments of clothianidin and other insecticides.

\section{ACKNOWLEDGEMENTS}

We thank Julie Sørlie Paus-Knudsen for help with laboratory work, and Malin R. Aarønes for comments on earlier drafts of the manuscript, both University of Oslo. We thank Dr. Dara Stanley (University College Dublin) for valuable input and useful discussions, and Dr. Clint Perry (Queen Mary University of London) for assistance in designing the bumblebee colony monitoring system. The study was financially supported by The Research Council of Norway through the project NEOPOLL (project number 268415).

\section{REFERENCES}

Aarønes R. M (2019) Accumulation of the neonicotinoid insecticide clothianidin in bumblebees (Bombus terrestris). Master thesis University of Oslo, Oslo, Norway. Retrieved from http://urn.nb.no/URN:NBN:no-73175

Basu P, Priyadarshini C (2015) Sub-Lethal Effects of Pesticides on Pollinators with Special Reference to Honey Bees. Mutualistic interaction between flowering plants and animals (pp. 174-184). Manipal University Press.

Bates D, Martin M, Ben B, Steve W (2015). Fitting Linear Mixed Effects Models Using Lme4. Journal of Statistical Software 1 (pp. 1- 48) 
Blacquière T, Smagghe G, Gestel C, Veerle M (2012). Neonicotinoids in Bees: A Review on Concentrations, Side-Effects and Risk Assessment. Ecotoxicology 21 (pp- 973-992).

Boina DR, Onagbola EO, Salyani M, Stelinski LL (2009). Influence of posttreatment temperature on the toxicity of insecticides against Diaphorina citri (Hemiptera: Psyllidae). Journal of Economic Entomology 102 (pp. 685-691)

Botías C, David A, Hill E, Goulson D (2016). Contamination of Wild Plants near Neonicotinoid Seed-Treated Crops, and Implications for Non-Target Insects. Science of The Total Environment 556-567 (pp 269-278)

Brown A., Ihara M, Buckingham S, Matsuda K, Sattelle D (2006). Neonicotinoid Insecticides Display Partial and Super Agonist Actions on Native Insect Nicotinic Acetylcholine Receptors. Journal of Neurochemistry 99 (pp. 608-615).

Bynum M, Smith W (2001). Floral Movements in Response to Thunderstorms Improve Reproductive Effort in the Alpine Species Gentiana Algida (Gentianaceae). American Journal of Botany 88 (pp. 1088-1095)

Camp A, Buchwalter D (2016). Can't take the heat: Temperature-enhanced toxicity in the mayfly Isonychia bicolor exposed to the neonicotinoid insecticide imidacloprid. Aquatic Toxicology 178 (pp. 49-57)

Crall J, Gravish N, Mountcastle A, Combes S (2015) BEEtag: A Low-Cost, Image-Based Tracking System for the Study of Animal Behavior and Locomotion. PLOS ONE 10 (9): e0136487

Cutler C, Rix R (2015). Can poisons stimulate bees? Appreciating the potential of hormesis in bee-pesticide research. Pest Management Science 71 (pp. 1368-1370)

Decourtye A, Armengaud C, Renou M, Devillers J, Cluzeau S, Gauthier M, Pham-Delègue M (2004). Imidacloprid Impairs Memory and Brain Metabolism in the Honeybee (Apis mellifera L.). Pesticide Biochemistry and Physiology 78 (pp. 83-92)

Déglise P, Grünewald, B, Gauthier M. (2002). The insecticide imidacloprid is a partial agonist of the nicotinic receptor of honeybee Kenyon cells, Neuroscience letters 321 (pp. 13-16)

Fischer J, Müller T, Spatz AK, Greggers U, Grünewald B and Menzel R (2014) Neonicotinoids Interfere with Specific Components of Navigation in Honeybees. PLOS ONE 9 (3):e91364

Feltham H, Park K, Goulson D (2014) Field realistic doses of pesticide imidacloprid reduce bumblebee pollen foraging efficiency. Ecotoxicology 23 (pp. 317323)
Free JB (1955) The Behaviour of Egg-Laying Workers of Bumblebee Colonies. The British Journal of Animal Behaviour 3 (pp. 147-153)

Free JB (1955) The division of labour within bumblebee Colonies. Insectes Sociaux 2 (pp. 195-212)

Gernat T, Rao V, Middendorf M, Dankowicz H, Goldenfeld N, Robinson G (2018) Automated Monitoring of Behavior Reveals Bursty Interaction Patterns and Rapid Spreading Dynamics in Honeybee Social Networks. Proceedings of the National Academy of Sciences 115 (pp. 1433-38)

Gill J, Ramos-Rodriguez O, Raine N (2012) Combined pesticide exposure severely affects individual- and colony-level traits in bees. Nature 491 (pp. 105-108)

Gill R and Raine N (2014). Chronic impairment of bumblebee natural foraging behaviour induced by sublethal pesticide exposure. Functional Ecology 28 (pp. 1459-1471).

Goulson, D (2013). An overview of the environmental risks posed by neonicotinoid insecticides. Journal of Applied Ecology 50 (pp. 977-987)

Han P, Niu CY, Lei CL, Cui JJ, Desneux N (2010) Use of an Innovative T-Tube Maze Assay and the Proboscis Extension Response Assay to Assess Sublethal Effects of GM Products and Pesticides on Learning Capacity of the Honey Bee Apis mellifera L. Ecotoxicology 19 (pp. 1612-1619)

Heinrich B. (1981). Insect Thermoregulation. John Wiley \& Sons, New York.

Ihara M, Matsuda K (2018) Neonicotinoids: molecular mechanism of action insights into resistance and impact on pollinators. Current Opinion in Insect Science 30 (pp. 86-92)

Intenthron M (1999) Making nests for bumble bees. Northern bee Books.

Kalnins M, Detroy B (1984). Effect of Wood Preservative Treatment of Beehives on Honey Bees and Hive Products. Journal of Agricultural and Food Chemistry 32 (pp. 1176-1180)

Kerr J, Pindar A, Galpern P, Packer L, Potts S, Roberts S, Rasmont P, Schweiger O, Colla S, Richardson L, Wagner D, Gall L, Sikes D, Pantoja A (2015). Climate change impacts on bumblebees converge across continents. Science 349 (pp 177-180).

Klein A, Vaissière, Cane J, Steffan-Dewenter I, Cunningham S, Kremen,C, Tscharntke T (2007) Importance of Pollinators in Changing Landscapes for World Crops. Proceedings. Proceedings of the Royal Society B-Biological Sciences 274 (pp, 303-313).

Kiljanek T, Niewiadowska A, Posyniak A (2016). Pesticide Poisoning of Honeybees: A Review of Symptoms, Incident Classification, and Causes of Poisoning. Journal of Apicultural Science 60 (pp. 5-24) 
Kumar S, Joshi P, Nath P, Singh V (2018) Impacts of Insecticides on Pollinators of Different Food Plants. Entomology, Ornithology \& Herpetology: Current Research 7 (pp. 1-6)

Lawson D, Rands S (2019) The effects of rainfall on plant-pollinator interactions. Arthropod-Plant Interactions 13 (pp. 561-569)

Lundberg H (1980) Effects of Weather on ForagingFlights of Bumblebees (Hymenoptera, Apidae) in a Subalpine/Alpine Area. Holarctic Ecology 3 (pp. 104110)

Lundberg H (2006) Effects of Weather on ForagingFlights of Bumblebees (Hymenoptera, Apidae) in a Subalpine/Alpine Area. Ecography 3 (pp. 104-110)

Mogren C, Lundgren J (2016) NeonicotinoidContaminated Pollinator Strips Adjacent to Cropland Reduce Honey Bee Nutritional Status. Scientific Reports 6 (p. 29608)

Nakagawa Y, Casida J (2001) Nicotinoid Insecticides and the Nicotinic Acetylcholine Receptor. Pest Management Science 57 (p. 102)

Nieto A, Stuart P, Roberts M, Kemp J, Rasmont P, Kuhlmann M, Criado M, Biesmeijer J (2014) European Red List of Bees. Luxembourg: Publications Office.

Ollerton J, Winfree R, Tarrant S (2011) How Many Flowering Plants Are Pollinated by Animals? Oikos 120 (pp. 321-326)

Oyen J, Dillon M (2018) Critical thermal limits of bumblebees (Bombus impatiens) are marked by stereotypical behaviors and are unchanged by acclimation, age or feeding status. Journal of Experimental Biology 221 (8): jeb165589.

Phelps J, Strang C, Sherry D (2020) Imidacloprid impairs performance on a model flower handling task in bumblebees (Bombus impatiens). Ecotoxicology 29 (pp. 359-374)

Potts R, Clarke R, Oldfield S, Wood L, Hempel de Ibarra N, Cresswell J (2018) The effect of dietary neonicotinoid pesticides on non-flight thermogenesis in worker bumble bees (Bombus terrestris). Journal of Insect Physiology 104 (pp. 33-39)

Potts S, Biesmeijer J, Kremen C, Neumann P, Schweiger O, Kunin W (2010) Global Pollinator Declines: Trends, Impacts and Drivers. Trends in Ecology \& Evolution 25 (pp. 345-353).

Potts S, Imperatriz-Fonseca V, Ngo H, Biesmeijer J, Breeze T, Dicks L, Garibaldi L (2016) Summary for Policymakers of the Assessment Report of the Intergovernmental Science-Policy Platform on Biodiversity and Ecosystem Services (IPBES) on Pollinators, Pollination and Food Production. IPBES secretariat, Bonn, Germany

R Core Team (2017) R: A language and environment for statistical computing. $\mathrm{R}$ Foundation for Statistical
Computing, Vienna, Austria. URL http://www.Rproject.org/

Samuelson E, Chen-Wishart Z, Gill J, Leadbeater E (2016). Effect of acute pesticide exposure on bee spatial working memory using an analogue of the radial-arm maze. Scientific Reports 6 (p.38957)

Sanborn A (2005) Thermoregulation in Insects. Encyclopedia of Entomology (pp. 2224- 2225). Springer Netherlands.

Stanley D, Smith J and Raine N (2015a). Bumblebee learning and memory is impaired by chronic exposure to a neonicotinoid pesticide. Scientific Reports 5 (p. 16508)

Stanley, D, Raine N (2016). Chronic exposure to a neonicotinoid pesticide alters the interactions between bumblebees and wild plants. Functional Ecology 30 (pp. 1132-1139)

Stanley D, Russell A, Morrison S, Rogers C, Raine N (2016). Investigating the impacts of field-realistic exposure to a neonicotinoid pesticide on bumblebee foraging, homing ability and colony growth. Journal of Applied Ecology 53 (pp. 1440-1449)

Sánchez-Bayo F, Wyckhuys K (2019) Worldwide Decline of the Entomofauna: A Review of Its Drivers. Biological Conservation 232 (pp. 8-27)

Schultze-Motel P (1991) Heat loss and thermoregulation in a nest of the bumblebee Bombus lapidaries (Hymenoptera, Apidae). Thermochimica Acta 193 (pp. 57-66)

Sibbald E, Plowright C (2013) Social Interactions and Their Connection to Aggression and Ovarian Development in Orphaned Worker Bumblebees (Bombus impatiens). Behavioural Processes 103 (pp. 150155)

Simon-Delso N, Amaral-Rogers V, Belzunces L, et al. (2015) Systemic Insecticides (Neonicotinoids and Fipronil): Trends, Uses, Mode of Action and Metabolites. Environmental Science and Pollution Research 22 (pp 5-34)

Sladen F (1989). The humble-bee, its life-history and how to domesticate it. Little Logaston, Woonton, Herfordshire: Logaston Press.

Soroye P, Newbold T, Kerr J (2020). Climate change contributes to widespread declines among bumblebees across continents. Science 367 (pp. 685-688)

Stelzer R, Chittka L (2010) Bumblebee foraging rhythms under the midnight sun measured with radiofrequency identification. BMC Biology 8 (p. 93)

Tackenberg M, Giannoni-Guzmán M, Sanchez-Perez E, Doll C, Agosto-Rivera J, Broadie K, Moore D, McMahon D (2020) Neonicotinoids disrupt circadian rhythms and sleep in honey bees. Scientific Reports 10 
Tasman K, Rands S, Hodge J (2020) The Neonicotinoid Insecticide Imidacloprid Disrupts Bumblebee Foraging Rhythms and Sleep. iScience 23 (12):101827

Tosi S, Démares F, Nicolson S, Medrzycki P, Pirk C, Human H (2016) Effects of a neonicotinoid pesticide on thermoregulation of African honey bees (Apis mellifera scutellata). Journal of Insect Physiology 93-94 (pp. 5663)

Tsvetkov N, Samson-Robert O, Sood K, Patel H, Malena D, Gajiwala P, Maciukiewicz P, Fournier V, Zayed A (2017). Chronic exposure to neonicotinoids reduces honey bee health near corn crops. Science 356 (pp. 1395-1397)

Williamson S, Wright G (2013) Exposure to Multiple Cholinergic Pesticides Impairs Olfactory Learning and Memory in Honeybees. The Journal of Experimental Biology 216 (pp. 1799-1807)

Williamson S, Willis S, Wright G (2014) Exposure to Neonicotinoids Influences the Motor Function of Adult Worker Honeybees. Ecotoxicology 23 (pp. 1409-1418)

Weidenmüller A (2004) The control of nest climate in bumblebee (Bombus terrestris) colonies: Interindividual variability and self-reinforcement in fanning response. Behavioral Ecology 15 (pp.120-128)

Vanbergen A, Insect Pollinators Initiative (2013) Threats to an Ecosystem Service: Pressures on Pollinators.
Frontiers in Ecology and the Environment 11 (pp. 251259)

Vaudo A, Stabler D, Patch H, Tooker J, Grozinger C, Wright G (2016) Bumble Bees Regulate Their Intake of Essential Protein and Lipid Pollen Macronutrients. The Journal of Experimental Biology 219 (pp. 3962-3970)

Xian-Xia L (2014) Toxicity of Insecticides to Bradysia odoriphaga at Different Temperatures and Their Control Effect in the Fields. Northern Horticulture 9 (pp. 125128)

Xu T, Dyer A, Mcconnell L, Bondarenko S, Allen R, Heinemann O (2015) Clothianidin in Agricultural Soils and Uptake into Corn Pollen and Canola Nectar after Multi-Year Seed Treatment Applications. Environmental Toxicology and Chemistry 35 (pp. 311321)

Yang EC, Chuang YC, Chen YL, Chang LH (2008) Abnormal Foraging Behavior Induced by Sublethal Dosage of Imidacloprid in the Honey Bee (Hymenoptera: Apidae). Journal of Economic Entomology (pp. 1743-1748)

Zambra E, Martinet B, Brasero N, Michez D, Rasmont P (2020). Hyperthermic stress resistance of bumblebee males: test case of Belgian species. Apidologie 51 (pp. 911-920). 